\title{
EDITORIAL
}

\section{In this Issue: Mixed Methods and Diverse Perspectives}

\author{
Kurt C. Stange, MD, PbD, Editor; Robin S. Gotler, MA, Reflections Editor \\ Conflicts of interest: none reported \\ Ann Fam Med 2006;4:290-291. DOI: 10.1370/afm.614.
}

\section{CLINICAL AND POLICY INSIGHTS FROM MULTIMETHOD RESEARCH}

$\mathrm{T}$

7 his issue features 6 research articles that use a multimethod design ${ }^{1-6}$ and an editorial ${ }^{7}$ that presents a typology of how to publish multimethod research. These studies show how qualitative and quantitative methods can inform and complement each other.

For example, the in-depth interview study by Rabago and colleagues ${ }^{1}$ builds on the findings of a previous randomized clinical trial ${ }^{8}$ and pragmatic follow-up study. ${ }^{9}$ These quantitative studies showed the effectiveness of nasal irrigation for reducing sinus symptoms, decreasing use of sinus medications, and improving quality of life among patients with chronic sinusitis. In the current study, patients from the previous studies were asked to tell their stories. Qualitative analyses showed that the treatment empowered patients to control important aspects of their health and health care and improved their quality of life in diverse ways. Further analyses of the interview data uncovered barriers to use of nasal irrigation and strategies to overcome those barriers. By listening to the patient participant's voice, this analysis offers clinicians and patients important information on how to implement an effective intervention and portrays the patient's actual experience in ways that the quantitative aspects of the study cannot. By making the quantitative findings "real," it empowers patients to understand what this treatment might mean for their lives, and it empowers clinicians to personalize therapy to individual patients.

The study by Wittink and colleagues ${ }^{2}$ also follows up on a long line of ongoing investigation, in this case, of how older primary care patients experience depression. The study in this issue examines patients' views of how interactions with their physicians influence the ways they communicate about depression. The findings provide important clues to how the interaction may affect the diagnosis of depression, and they may help to explain both underdiagnosis and differences in diagnosis by race, culture, and sex.

Companion articles by Solberg and colleagues ${ }^{3}$ and Hroscikoski and colleagues ${ }^{4}$ report the quantitative and qualitative findings, respectively, of a multimethod study. This study evaluated implementation of the Chronic Care Model, which is being widely used to guide practice and health care system reform..$^{10-12}$ The quantitative findings, ${ }^{3}$ limited by small sample size and a pre-post design, show improvements in care for 3 chronic illnesses; however, only 2 Chronic Care Model elements-clinical information systems and decision support-are associated with improvements in care for one of the chronic illnesses, diabetes. The qualitative component of the study ${ }^{4}$ reveals the meaning of the quantitative findings. By using multiple data sources to examine 5 of 18 participating practices in depth, this analysis shows the health care system and practice contexts for the intervention-essential information for others attempting to translate the findings into their practice settings. These findings show that the limited initial effect of the intervention caused participants to change their strategies in ways that did not build on the strengths of previously successful change interventions. Findings about competing priorities and the challenges of specifying components of the model should be useful to others attempting to implement or adapt the Chronic Care Model to improve care.

The study by Sussman and colleagues ${ }^{5}$ mixes interviews, focus groups, and a survey to take an in-depth look at the decision to undertake preventive counseling for obesity. The findings from this on-the-ground perspective in real-world practices provide a welcome complement to previous health services research. Earlier research has provided the view from 10,000 feet 
and, as a result, has yielded simplistic solutions to a problem that this study finds to be complex. The identification of stable factors that set the stage for counseling, coupled with dynamic factors during the visit, provide a framework for more creative and realistic interventions in the future.

Bennett and colleagues ${ }^{6}$ use a quantitative sampling frame to identify women with inadequate prenatal care, and then they follow up with individual interviews and focus groups. They found that communication with clinicians is an important factor influencing prenatal care use. This potentially mutable factor and the specific ideas about "breaking it down" point to novel next steps for interventions to improve prenatal care use.

\section{OTHER ARTICLES OF CLINICAL AND POLICY INTEREST}

Many studies show that patients' pain is poorly managed at all levels of the health care system. In a randomized clinical trial in 14 rural primary care practices, Ahles and colleagues show that patients with pain and psychosocial problems improve with telephone assistance by a nurse-educator. ${ }^{13}$ The intervention appears to be well integrated into primary care, improving not only patients' bodily pain but also role function, vitality, and emotional function compared with usual care. The sustained effect at 12 months is remarkable, considering that the average patient received only 3 telephone calls.

Recent concerns about bioterrorism have generated interest in strategies for early identification of symptom complexes that could be associated with various illnesses. A study in a primary care practice finds that syndromic surveillance using billing data is feasible and shows earlier identification of an increase in cases of influenza than do data from emergency departments in 5 adjacent counties. ${ }^{14}$ It appears that billing data from primary care practice can be used to identify emerging infections in the community. With a bit of ongoing infrastructure support, practice networks can conduct ongoing surveillance to meet a number of needs. This idea is not new, ${ }^{15}$ but this proof of its feasibility and possible superiority to emergency department surveillance argues for the development of sustained support systems.

In a provocative study of a nationally representative sample, Viera and colleagues find that $20 \%$ of US adults do not have a usual source of care. ${ }^{16}$ For most people, this lack of a medical home is due to their preference. It is also, however, associated with lack of insurance, male sex, excellent reported health, younger age, and Hispanic ethnicity. This study can help to identify those who are excluded from a medical home vs those who choose to be medically homeless and can lead to targeted interventions to foster access to a medical home.

The essay in this issue ${ }^{17}$ makes the case that house calls are not a relic of family medicine's past but a potential key to the future. Landers finds house call practice to be financially viable, as well as satisfying for both patients and clinicians.

We encourage readers to join the Annals online discussion at http://www.AnnFamMed.org.

To read or post commentaries in response to this article, see it online at http://www.annfammed.org/cgi/content/full/4/4/290.

\section{References}

1. Rabago D, Barrett BP, Marchand L, Maberry R, Mundt M. Qualitative aspects of nasal irrigation use by patients with chronic sinus disease in a multi-method study. Ann Fam Med. 2006;4:295-301.

2. Wittink MN, Barg F, Gallo JJ. The unwritten rules of talking to doctors about depression: integrating qualitative and quantitative methods. Ann Fam Med. 2006;4:302-309

3. Solberg LI, Crain AL, Sperl-Hillen JM, Hroscikoski MC, Engebretson $\mathrm{KI}, \mathrm{O}$ 'Connor PJ. Care quality and implementation of the chronic care model: a quantitative study. Ann Fam Med. 2006;4:310-316.

4. Hroscikoski MC, Solberg LI, Sperl-Hillen JM, Harper PG, McGrail M, Crabtree BF. The challenges of change: implementing the chronic care model. Ann Fam Med. 2006;4:317-326.

5. Sussman AL, Williams R, Leverence R, Gloyd Jr. P, Crabtree BF. The art and complexity of primary care clinicians? preventive counseling decisions: obesity as a case study. Ann Fam Med. 2006;4:327-333.

6. Bennett IM, Switzer J, Aguirre A, Evans K, Barg F. 'Breaking it down': patient-clinician communication and prenatal care among African American women of low and higher literacy. Ann Fam Med. 2006;4:334-340

7. Stange KC, Crabtree BF, Miller WL. Publishing multimethod research. Ann Fam Med. 2006;4:292-294

8. Rabago D, Zgierska A, Mundt M, Barrett B, Bobula J, Maberry R. Efficacy of daily hypertonic saline nasal irrigation among patients with sinusitis: A randomized controlled trial. J Fam Pract. 2002; 51:1049-1055.

9. Rabago D, Pasic, Zgierska A, Barrett B, Mundt M, Maberry R. The efficacy of hypertonic saline nasal irrigation for chronic sinonasal symptoms. Otolaryngol Head Neck Surg. 2005; 133:3-8.

10. Wagner EH, Austin BT, Von Korff M. Organizing care for patients with chronic illness. Milbank Q. 1996; 74:511-544.

11. Wagner EH, Austin BT, Davis C, Hindmarsh M, Schaefer J, Bonomi A. Improving chronic illness care: translating evidence into action. Health Aff (Millwood). 2001; 20:64-78.

12. Von Korff M, Glasgow RE, Sharpe M. Organising care for chronic illness. BMJ. 2002; 325:92-94.

13. Ahles TA, Wasson JH, Seville J, et al. A controlled trial of methods for managing pain in primary care patients with or without cooccurring psychosocial problems. Ann Fam Med. 2006;4:341-350.

14. Sloane PD, MacFarquhar J, Sickbert-Bennett E, et al. Syndromic surveillance for emerging infections in office practice using billing data. Ann Fam Med. 2006;4:351-358.

15. Green LA, Wood M, Becker L, et al. The Ambulatory Sentinel Practice Network: purpose, methods, and policies. J Fam Pract. 1984; 18:275-80

16. Viera AJ, Pathman DE, Garrett J. Adults' lack of a usual source of care: a matter of preference?. Ann Fam Med. 2006;4:359-365.

17. Landers SH. Home care: a key to the future of family medicine? Ann Fam Med. 2006;4:366-368. 